\title{
Electronic waste recovery in Finland: Consumers' perceptions towards recycling and re-use of mobile phones
}

\author{
Jenni Ylä-Mella ${ }^{a}{ }^{*}$, Riitta L. Keiski ${ }^{b}$ and Eva Pongrácz ${ }^{a}$ \\ a Centre of Northern Environmental Technology (NorTech Oulu), Thule Institute, University of Oulu, \\ P.O. Box 7300, FIN-90014 Oulu, Finland \\ ${ }^{b}$ Environmental and Chemical Engineering, Faculty of Technology, University of Oulu, \\ P.O. Box 4300, FIN-90014 Oulu, Finland
}

\begin{abstract}
This paper examines consumers' awareness and perceptions towards mobile phone recycling and re-use. The results are based on a survey conducted in the city of Oulu, Finland, and analysed in the theoretical framework based on the theories of planned behaviour (TPB) and value-belief-norm (VBN). The findings indicate that consumers' awareness of the importance and existence of waste recovery system is high; however, awareness has not translated to recycling behaviour. The survey reveals that $55 \%$ of respondents have two or more unused mobile phones at homes. The more phones stored at homes, the more often reasons 'I don't know where to return' and/or 'have not got to do it yet' were mentioned. This indicates that proximity and the convenience of current waste management system are inadequate in promoting the return of small waste electrical and electronic equipment (WEEE). To facilitate re-use, and the highest level of recovery, consumers will need to be committed to return end-of-use electronics to WEEE collection centres without delays. Further, the supply and demand of refurbished mobile phones do not meet at this moment in Finland due to consumer's storing habits versus expectations of recent features under guarantee and unrealistic low prizes. The study also points out that, in order to change current storing habits of consumers, there is an explicit need for more information and awareness on mobile phone collection in Finland, especially on regarding retailers' take-back.
\end{abstract}

Keywords: WEEE recovery network, Environmental awareness, Recycling, Re-use, Mobile phone, Finland.

\footnotetext{
* Corresponding author. Tel.: +358 294487559

E-mail addresses: jenni.yla-mella@oulu.fi (J. Ylä-Mella), riitta.keiski@oulu.fi (R.L. Keiski), eva.pongracz@oulu.fi (E. Pongrácz)
}

\section{Introduction}

The primary goal of the European Union's (EU) waste legislation is to prevent waste generation and to promote re-use, recycling and other forms of recovery. That is also the case for waste electrical and electronic equipment (WEEE); the WEEE Directive (2002/96/EC) was implemented first time in January 2003. After some difficulties and unequal development of operational and legislative progress in the first years of implementation, the WEEE Directive has been transposed to national legislations and operational preconditions have been built up in all EU Member States. In addition, also Norway, Lichtenstein and Switzerland as countries of European Economic Area (EEA) have followed up the EU legislation. As a rule, an initial collection target of $4 \mathrm{~kg} /$ inhab./year has been achieved in most of the countries; only some of the newest Member States have had challenges to reach the target; the WEEE collection amounts ranged from $1.2 \mathrm{~kg} / \mathrm{inhab}$. in Romania to 
$22.0 \mathrm{~kg} / \mathrm{inhab}$. in Norway in 2010. (Environmental Data Centre on Waste, 2014) The broad variety reflects not only the extent of national collection networks but also the differences in electrical and electronic equipment (EEE) consumption levels within Europe.

Total tonnages of collected WEEE in Europe are mainly on good or even excellent levels when compared to the current annual collection requirement of $4 \mathrm{~kg}$ per inhabitant. However, if collected amounts are compared to the EEE amounts put on the market (POM), there is still room to improve the collection rates (see Fig. 1). Therefore, the recast WEEE Directive (2012/19/EU), which entered into force on 13 August 2012, set a specific collection target for each Member State. According to the recast Directive, the rate of separate collection of at least $4 \mathrm{~kg} / \mathrm{inhab}$./year of WEEE from private households, or the same amount of WEEE that was collected in the three preceding years, whichever is greater, has to be collected (Directive 2012/19/EU). In the case of Finland, that means at least $9 \mathrm{~kg} / \mathrm{inhab}$. of WEEE has to be collected annually since 2014 (Ministry of the Environment in Finland, 2014). Moreover, the recast Directive introduced also a new collection target resting on national consumption levels. From 2016 onward, the national collection target will be defined as the ratio between the collected amount and the average weight of the annual EEE put on the market in the three preceding years. In 2016, the target is set at $45 \%$ and it will rise to $65 \%$ in 2019 (Directive $2012 / 19 / \mathrm{EU}$ ).



Fig. 1. Collection rate for WEEE in 2010 as a percentage of the average weight of EEE put on the market in the three preceding years (2007 - 2009) in the EU and Norway (Environmental Data Centre on Waste, 2014).

According to the EU statistics, only five of the current $28 \mathrm{EU}$ Member States and Norway have already achieved the 45\% target in 2010; Sweden even exceeded the 65\% collection target (Eurostat, 2014). On the contrary, there are still five Member States which have achieved only low collection rates between $10 \%$ and $20 \%$. When considering the case of Finland, the collection rate is at a good average level of $32 \%$ in 2010 ; however, relatively high collection improvements are needed to achieve the target set for 2016 (Eurostat, 2014). 
When collected WEEE is considered by equipment category, large household appliances (category 1) accounted for over $40 \%$ of the total weight in the EU in 2010 (Eurostat, 2014). IT and telecommunication equipment (cat. 3) and consumer equipment (cat. 4) were the next important categories in terms of quantity, both with a share of around $20 \%$. Further, small household appliances (cat. 2) contributed approximately $6 \%$ to WEEE collection (Eurostat, 2014). However, the returns of appliances lighter than $1 \mathrm{~kg}$ are very low (Huisman et al., 2007). Several studies indicate that a large fraction of small EEE do not currently enter the WEEE recovery systems but are not in use (Chancerel, 2010; Gutiérrez, et al., 2010; Ongondo and Williams, 2011; Pérez-Belis et al. 2013; Polák and Drápalová, 2012; Tanskanen and Butler, 2007). Considering that they are often functional equipment, we do not consider them end-of-life (EOL) equipment, but rather end-of-use, indicating their potential use prospect (Pongrácz et al., 2008). EOL equipment, on the other hand, is often disposed by inappropriate ways such as in misplaced waste fractions (Bernstad et al., 2011, 2012; Bigum et al., 2013; Krook and Eklund, 2010) or with mixed waste (Bernstad et al., 2011, 2012; Darby and Obara, 2005; Gutiérrez et al., 2010; Melissen, 2006; Pérez-Belis et al., 2013).

\subsection{The aim of the study}

To achieve good collection rates of WEEE, the most important factor to be considered is how to ensure the participation of end-users. That is also the case in Finland; based on the authors' earlier research (YläMella et al., 2014) it seems that providing up-to-date information and increased publicity on prevailing practices would be actual needed in Finland, in order to raise public awareness related to WEEE recovery and achieve environmentally sound behaviour on the long term. In our earlier paper (2014) we argued that the re-use potential of EOL electronics is not significantly used in Finland. Therefore, this study was conducted in order to investigate consumers' awareness, perceptions and behaviour related to the recycling and re-use of electronic waste. The study was conducted as a survey in 2013, with the aim to examine residents' awareness and perceptions related to the current WEEE recovery system in the city of Oulu, which was the case study also in authors' earlier research (Ylä-Mella et al., 2014) concerning the Finnish WEEE recovery network. Mobile phones were selected as a case study device of the survey as they represent a typical, small, hightech consumer device with a short lifecycle and substantial contents of valuable materials.

The survey was a descriptive case study with a theoretical framework based on the theory of planned behaviour (TPB) developed by Ajzen (1991) and Value Belief Norm (VBN) Theory by Stern (2000). Moreover, Motivation-Ability-Opportunity-Behaviour Model by Ölander and Thøgersen (1995) and Model of ProEnvironmental Behaviour by Kollmuss and Agyemann (2002) have been applied in this study. The survey was qualitative by nature but supported by quantitative analysis. This means that the themes within the research questions were quantified for further discussion. The objective was to provide answers to the following research questions:

RQ 1: What are the reasons of failing to return mobile phones for recycling?

RQ 2: Are consumers aware of possibilities to return WEEE and what are consumers' perceptions related to feasibility of the current WEEE collection network in the Oulu Region?

RQ 3: Are consumers aware of the importance of mobile phone recycling?

RQ 4: What are the consumers' perceptions toward re-use of mobile phones? 
It was expected that the survey provides knowledge for a wide audience: shorter term information related to feasibility of the current system for local practical operators and long term behavioural know-how for producers associations and authorities when planning the nationwide WEEE take back intensification due to upcoming tighter collection requirements.

\section{Background}

\subsection{The convenience of recycling}

Source separation has already become a kind of a norm in many communities, when separating dry recyclables is a common activity amongst individuals and households in many parts of the world (Thomas and Sharp, 2013). However, provision of services and the awareness of recycling have an important role in whether or not to participate; perceptions of convenience and familiarity with local waste facilities enhance the recycling action ${ }^{1}$ (Barr et al., 2001; Saphores et al., 2006; Thomas and Sharp, 2013; do Valle et al., 2004). Several studies show that the inconvenience of recycling schemes and economic disincentives (e.g. return fees, extra trips) lower the participation and recovery rates (Barr et al., 2001; Wagner, 2013; Bouvier and Wagner, 2011), which seems to be the case also in many WEEE recycling schemes (Saphores et al. 2012; Wang et al., 2011; Yin et al., 2013). However, some studies also found no correlation between the existing facilities and actual recycling actions (Miafodzyeva et al., 2013; Ramayah et al., 2012). Miafodzyeva et al. (2013) have studied the recycling behaviour of households living in multicultural urban area in Stockholm, Sweden. They found that the satisfaction with the facilities provided did not correlate with recycling behaviour but the most widespread motive for participating was acceptance of legal norms (Miafodzyeva et al., 2013). Also the study of Ramayah et al. (2012) carried out in Malaysia found that norms have an overwhelming influence on recycling behaviour in a collectivistic society compared to individual convenience.

Wagner (2013) has examined in depth the concept of convenient collection. He argues that collection systems within the framework of Extended Producer Responsibility (EPR), such as the collection systems for WEEE, are typically developed fairly rapidly and, therefore, insufficient attention has been paid to ensure that collection systems are as convenient as possible. On the other hand, Wagner (2013) also states that the term of convenience is a subjective construct and, therefore, individuals have different perceptions regarding a convenient collection system. To help assess the convenience of a collection system, Wagner (2013) has identified various categories of convenience: the five elementary components of convenience are (1) knowledge requirements, (2) proximity to the collection point/site, (3) opportunity to drop-off materials, (4) inducement of the collection point/site (e.g. desirability or availability of services), and (5) ease of the process. According to Wagner (2013), a collection system with high convenience includes easily obtainable and centrally located multiple collection points with no accessibility or temporal restrictions and requires minimal efforts to obtain and/or provide information in the course of returning procedures.

\subsection{Life time extension of EEE}

Technical innovations and electrical and electronic equipment (EEE) becoming a part of everyday life have significantly increased the production and use of EEE during the last three decades. As a consequence

\footnotetext{
${ }^{1}$ For the sake of convenience, we use the term 'recycling behaviour' when consumers are segregating their wastes at homes and are returning them to the collection system.
} 
of invariably new applications especially in IT and telecommunications equipment the amount of WEEE has grown exponentially (Ongondo et al., 2011). Recently, a useful life time of existing EEE has been reduced due to ever faster release of devices with new features (Cox et al., 2013; Kissling et al., 2012; Saphores et al., 2012; Yin et al., 2013).

Cox et al. (2013) have studied consumer understanding of product lifetimes. In their study, a new product typology based on product lifetime preferences were identified; the three classes of product are 'up-to-date', 'workhorse', and 'investment' products. According to Cox et al. (2013), most consumer electronics and small EEE are considered 'up-to-date' products with expected lifetimes of less than five years. Moreover, these products are typically discarded before the end of their functional life for reasons of keeping up with technological advances or personal feeling of success in life. A lifetime of 'workhorse' products is more closely related to functional durability. They are mostly used as long as they work properly; however, they are ordinarily replaced immediately when break down due to feelings of expensive or difficult repair and low cost of replacement. The third class, 'investment' products, have generally longer life time than other classes, because of consumers feelings of greater financial and/or emotional investment put into the products in the course of procurement. Consumers also tend to treat investment products carefully in use and are willing to pay for repairing because the initial investment makes the value of repair more apparent. (Cox et al., 2013) 'Workhorse' and 'investment' products are not considered in our study because small EEE are mostly regarded as 'up-to-date' products.

The re-use sector for EEE has grown steadily over the last decades; however, there is still a lot of latent potential (Babbitt et al., 2011; Kissling et al., 2012; Peagam et al., 2013). Generic re-use operating models for EEE as well as success factors and barriers in re-use of EEE have recently been investigated by Kissling et al. (2012, 2013). In the study of Kissling et al. (2012), a typology was defined to provide a more concise description of different re-use activities. Generic re-use operating models were identified for ICT and large household appliances (LHA) because both categories have currently large and steadily growing re-use markets. Kissling et al. (2012) identified four operating models, which differ from each other in terms of their financial orientation, offering and customer segments. Further, the success factors and barriers in the re-use of EEE were identified by Kissling et al. (2013) through the semi-structured personal interviews with representatives of organisations with different operating models. Based on the study, the most important success factors are related to quality of used EEE, process practices during the preparation for re-use, and stakeholder relationships, while factors related to documentation and reporting and cost and revenues were ranked least important. Respectively, according to Kissling et al. (2013), the most important barriers are related to the access to sufficient volumes of used, good-quality equipment and existing informal or illegal re-use practices. Barriers related to regulations, standards, product design and costs were identified as well. (Kissling et al., 2013)

For improving the access to sufficient volumes of good quality EOL EEE, the studies of Babbitt et al. (2011) and Peagam et al. (2013) have focused on EOL management practices of institutional and businessto-business (B2B) ICT devices. In EU, only a small percentage of B2B WEEE is reported to be collected in compliance with the WEEE Directive. Therefore, Peagam et al. (2013) conducted a survey to find out how EOL B2B devices are managed in the UK, Germany and France. They found that smaller organizations disposed of their devices through informal arrangements while larger ones disposed them of through contractors. This means that B2B devices are likely to enter recycling streams where they are not reported. Notwithstanding, 
recycling and refurbishment of B2B ICT devices at the end of use seem to be commonplace in the EU (Peagam et al., 2013). The study of Peagam et al. (2013) also showed that the majority of devices reached their EOL after 3 to 4 years or in 3 years if the units had fixed replacement periods. Peagam et al. (2013) note, that product lifetimes for B2B are shorter than for B2C and, therefore, there could be an untapped use potential and the likelihood of financial value for B2B devices.

Also Babbitt et al. (2011) have studied the re-use potential and economic value of institutional EOL ICT devices. They found that especially laptops and desktop computers have a great revenue stream of re-use compared to other EOL practices due to the high frequency of purchases by individuals. Babbitt et al. (2011) state that the resale of institutional electronic devices is not only economically worthwhile, but also provide access to computers for those who may not be able to obtain new equipment and extend the product lifetime by delaying equipment to enter a waste stream. However, they underline that eliminating the storage phase of end-of-first-life products is vital, and the ability to direct devices immediately to appropriate EOL management increases the potential for refurbishment and re-use (Babbitt et al., 2011). Computer leasing systems have been lauded as a sustainable practice because it has been expected to contribute to the refurbishment and re-use rate of EOL B2B computers (Babbitt et al., 2011). However, Babbitt et al. (2011) argue that leasing by itself does not automatically ensure environmental benefits because the fixed replacement periods are typically shorter that the functional lifetime of most EEE. Therefore, they suggest considering replacement cycles of EEE more case-specifically, against the spectrum of equipment lifetime in question (Babbitt et al., 2011).

The main challenges of increasing re-use rise from the contradiction between legislation and the benefits of producers. The most recent European WEEE legislation provides an increased motivation for re-use; however, producers may regard re-use as a conflict of interest; the total sales may be increased through a better environmental image or, on the contrary, re-use may reduce sales volumes of new equipment in parallel with increased WEEE collection cost. Further, it is suggested, that the image of re-use can also hurt the brand image of companies producing high-tech fashion-conscious devises (Herold, 2007).

\subsection{Awareness and incentives for recycling}

In addition to creating an adequate recycling infrastructure, recycling efforts can be stepped up by raising consumers' awareness e.g. informing them about practical advices related to current recycling practices, importance of recycling, and even others' recycling efforts (Staats et al., 2004). A number of studies has shown that increased information and environmental awareness enhance public participation in recycling (Ramayah et al., 2012; Saphores et al., 2012; Thomas and Sharp, 2013; do Valle et al., 2004). On the other hand, Thomas and Sharp (2013) claim that recycling has already become so strong as a social norm, that it has been found to hinder moves towards the more sustainable activity of reducing or preventing waste. Recycling has also been found to be used to compensate for other less sustainable behaviours such as taking airplane trips or discarding products only for reasons of changing fashion (Thomas and Sharp, 2013; Cox et al., 2013). Therefore, Thomas and Sharp (2013) emphasize the importance of greater understanding of positive and negative spillovers in designing interventions to encourage recycling and other pro-environmental behaviours.

Recently, implementing economic incentives to foster WEEE recycling has been proposed (Arditi, 2014; Milovantseva and Saphores, 2013; Yin et al., 2013). Although implementation of well-designed deposit refund systems (e.g. for aluminium, other metals, glass, plastics, batteries) has been shown economically more profitable than other economic instruments, such as taxes on virgin materials, recycling subsidies, recycling 
content standards or waste disposal fees (Fullerton and Kinnaman, 1995; Palmer et al., 1997; Saphores et al., 2012; Saphores and Nixon, 2014; Sigman 1995), creating economic incentives in a large scale for fostering WEEE recycling has not been seriously considered yet (Milovantseva and Saphores, 2013; Saphores et al., 2012). Notwithstanding, different incentives have been offered for mobile phones over the years (Ongondo and Williams, 2011; Tanskanen, 2013). Ongondo and Williams (2011) have investigated the UK mobile phone take-back network. They found that most of the UK schemes provide incentives but less than half of them offer direct monetary payment. Current incentives include discounts or free services for mobile phone usage and certain free returning options, such as courier collection or postage services for old mobile phones and their accessories. Tanskanen (2013) describes, from the manufacturer's point of view, mobile phone recycling campaigns carried out in cooperation with PROs, telecommunication operators, retail chains, recycling companies, environmental NGOs, and schools or universities. To attract consumers to participate in these recycling programs initiated by Nokia, various incentives have been offered ranging from prepaid phone cards to eco-friendly shopping bags or tree planting (Tanskanen, 2013). Eventually, based on good experiences gained in incentives implemented in the mobile phone recovery combined with current low recycling rates of WEEE, Ongondo and Williams (2011), Milovantseva and Saphores (2013) and Saphores and Nixon (2014) suggest to give serious consideration of implementing deposit-refund systems also for WEEE recycling.

\section{The survey}

\subsection{The case area of Oulu}

The city of Oulu is the capital of Northern Finland situated in Northern Ostrobothnia, on the coast of Bay of Bothnia. Oulu and its surrounding municipalities have over 200,000 inhabitants being the fourth most populous city area in the country and, furthermore, one of the fastest growing regions in Finland. In the Oulu area, the municipal waste management system is managed regionally by the Oulu Waste Management Company. In 2013, its operating area consisted of 12 municipalities with the total area of $13,760 \mathrm{~km}^{2}$ serving around 290,000 residents.

In the case of WEEE from households, the Oulu Waste Management Company maintains in its operating area a total of 11 manned reception points, where consumers can return their WEEE free of charge. The main reception point of WEEE is situated in the premises of the Oulu Waste Management Company, while smaller reception points are located in connection with the company's waste stations in rural population centres of the Oulu region. (Oulu Waste Management Company, 2014) Consumers can also return their EOL EEE to the retailers in association with buying a new, corresponding device or, in addition to cases of small WEEE, with no purchase obligations (Ministry of the Environment in Finland, 2011).

\subsection{Execution of the survey}

The survey was conducted by questioning arbitrarily selected respondents. One third of the questionnaires (50 copies) were distributed coincidentally to a large work community, while the rest of the questionnaires (100 copies) were delivered to the letterboxes of detached or terraced houses or private apartments across the City of Oulu within the postal codes of 90230 and 90540 . The postal area of 90230 is located within approximately $2 \mathrm{~km}$ eastward from the city centre of Oulu and it consists mainly of terraced and detached houses built in 1970's. The area of 90540 , for one, is a newer residential area built over the last ten years, located $12 \mathrm{~km}$ 
northward from the city centre. The area comprises of a wide variety of one-family and semi-detached houses, but also owner-occupied and rental apartment buildings. From that area, rental apartment buildings were included in the survey. The questionnaires were requested to be returned anonymously within pre-paid return envelopes trough public postal services. The responses received were analysed by the IBM SPSS Statistics program, version 21.

\subsection{The questionnaire}

A bilingual questionnaire (double-sided in Finnish and in English) consisted of a total of 19 multiple-choice and open-ended questions. In multiple-choice questions, respondents (abbreviation $R$ used in figure captions) were able to choose one or more options (abbreviation $n$ used in figures), when needed. Further, respondents were asked to underline the most important option if choosing more than one.

The first questions of the questionnaire concentrated on respondents recycling behaviour and reasons leading to current situation. For a start, respondents were asked, if they have unused mobile phones at homes and what are reasons for that. Respondents' personal recycling actions and perceptions for usability of the current WEEE collection network were enquired next and, lastly, some habits related to changing a mobile phone were sought. Questions concerning recycling behaviours are gathered up to Table 1.

\section{Table 1}

Questions related to consumers' recycling behaviour.

\begin{tabular}{|c|c|}
\hline No. & Question \\
\hline 1 & Do you have old and unused mobile phones at home? If yes, how many? \\
\hline \multirow[t]{7}{*}{$2 a$} & What do you do with old and unused mobile phones? \\
\hline & 1. I keep them at home \\
\hline & 2. I give them e.g. to my children/relatives \\
\hline & 3. I sell them \\
\hline & 4. I leave them at the store when buying a new one \\
\hline & 5. I take them to the recycling centre \\
\hline & 6. I dispose them with mixed waste \\
\hline $2 b$ & If you keep old mobile phones at home, please give a reason why? \\
\hline 2c & $\begin{array}{l}\text { If you have taken your old phones to the recycling centre, please tell where, and where did you hear about } \\
\text { this opportunity from? }\end{array}$ \\
\hline $2 d$ & In your opinion, was it simple or troublesome to take old mobile phones to the recycling centre? Why? \\
\hline \multirow[t]{6}{*}{3} & If you have not taken your old mobile phones to the recycling centre, what is the reason? \\
\hline & 1. I keep it as a spare phone \\
\hline & 2. I don't know where to take it \\
\hline & 3. I feel that recycling is troublesome \\
\hline & 4. I have not gotten around to do it yet \\
\hline & 5. Other, what? \\
\hline $4 b$ & Have you ever disposed of a mobile phone with mixed waste? \\
\hline \multirow[t]{5}{*}{$19 a$} & $\begin{array}{l}\text { How frequently you change a mobile phone? What is your most common reason to change a mobile phone to } \\
\text { a newer one? }\end{array}$ \\
\hline & 1. More often than one year \\
\hline & 2. 1-2 years \\
\hline & 3. 2-3 years \\
\hline & 4. Less frequently; how seldom? \\
\hline \multirow[t]{5}{*}{$19 b$} & What is your most common reason to change a mobile phone to a newer one? \\
\hline & 1. The old one doesn't work anymore \\
\hline & 2. Company-owned phones are changed regularly \\
\hline & 3. The latest models have novel features \\
\hline & 4. Other, what? \\
\hline
\end{tabular}


The second part of the questionnaire concentrated on consumer awareness related to WEEE recovery and legislative issues of WEEE. First, respondents were enquired if they agreed to dispose a mobile phone with mixed waste and, alternatively, what they were thinking of mobile phone recycling. They were also asked if they were aware of Finnish WEEE legislation and if they have seen the symbol for the marking of EEE according to the WEEE Directive. Finally, a question concerning financial issues of WEEE recovery was asked. Questions of consumers' awareness related to WEEE recovery and mobile phones recycling are compiled in Table 2.

\section{Table 2}

Questions related to consumers' awareness of WEEE recovery and legislative issues.

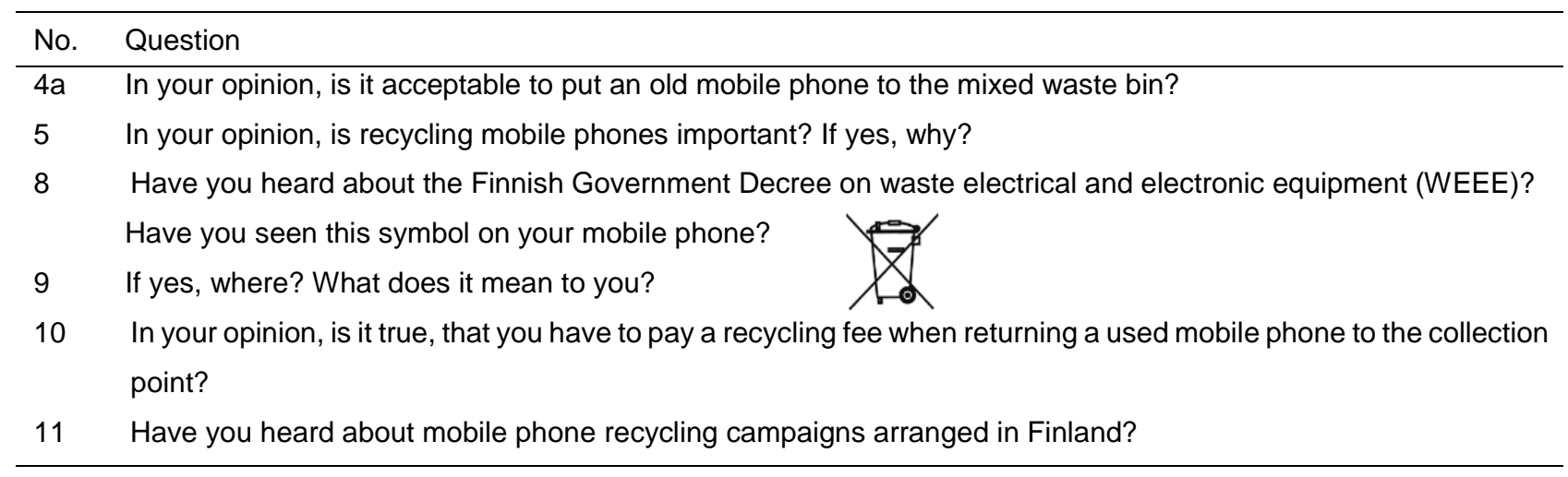

In the third part of the questionnaire, respondents' perceptions and attitudes towards re-use of mobile phones were investigated. First, consumers were asked to assess an appropriate sum of money as an incentive to return their old, end-of-use mobile phones through a fictitious deposit system. Respondents were also enquired for their willingness to buy a used mobile phone. If they agreed to the idea, opinions for prerequisites and suitable prices were asked. Respectively, if they disagreed, respondents were requested to indicate reasons for not buying a used mobile phone. Questions related to re-use are presented in Table 3.

\section{Table 3}

Questions related to consumers' perceptions toward mobile phone re-use and monetary incentives for returning of old mobile phones.

\begin{tabular}{|c|c|}
\hline No. & Question \\
\hline 6 & $\begin{array}{l}\text { Imagine that a deposit system similar to returnable bottles was operational for mobile phones. What would be } \\
\text { the sum of money (min. } € \text { - max. } € \text { ) that would motivate you to return your old mobile phone through the deposit } \\
\text { system? }\end{array}$ \\
\hline $7 a$ & Would you be willing to buy a used mobile phone? \\
\hline $7 b$ & $\begin{array}{l}\text { What would be your prerequisites for buying a used mobile phone? If you choose more than one, please, } \\
\text { underline the most important option. } \\
\text { 1. Mobile phone is no more than one year old } \\
\text { 2. It has features that my current one does not have } \\
\text { 3. It is cheaper to buy a used phone than a new one } \\
\text { 4. I know the last owner/ buy it at first hand } \\
\text { 5. Other, what? }\end{array}$ \\
\hline $7 c$ & How much would you be willing to pay for a used mobile phone (max. $€$ or $\%$ of original price)? \\
\hline $7 \mathrm{~d}$ & If you would not be willing to buy an old mobile phone, please, indicate why. \\
\hline
\end{tabular}




\section{Results}

\subsection{Respondents}

In total, 53 persons (response rate 35.3\%) participated in the survey, from which 24 (or $45.3 \%$ ) were males and 29 (or $54.7 \%$ ) females. Almost $65 \%$ of respondents lived in one-person (15\%) or two-person households (49\%). Further, around $26 \%$ of respondents had a household size of three or four, and the rest $9 \%$ of the respondents lived in the household of 5 persons or more. Respondents' ages varied widely and were evenly spread: $26 \%$ of the respondents were in the age range of $20-34$, and around $30 \%$ between 35 and 50 years. Moreover, $19 \%$ were in the age of $51-64$, while almost $23 \%$ were above the age of 65 years. Only one of the respondents (2\%) was under the age of 20 years.

Respondents' educational level was very high; up to $79 \%$ of the respondents had a polytechnic or university degree, while only $7.5 \%$ had an education equivalent to upper secondary school or lower. However, the household's gross income per month was broadly segmented: around $26 \%$ of households had monthly incomes between 4000 and 5999 euros, while 34\% of households remained under 4000 euros and, on the other hand, as much as $20 \%$ of households reached 8000 euros per month. When asking respondent's current occupations, the most common answers were full-time worker (53\%) and pensioner (26\%) but also some parttime workers $(9 \%)$, students $(6 \%)$ and home makers $(4 \%)$ had returned the questionnaire. Only one of the respondents $(2 \%)$ entered entrepreneur as a profession.

\subsection{Consumers' recycling behaviour}

Most of the respondents (45) had end-of-use mobile phones at homes (see Fig. 2). Sixteen respondents $(30 \%)$ kept just one extra phone at home, whereas 25 of respondents (47\%) stated to have 2 to 5 phones not in use; however, two persons admitted to have 10 or more unused mobile phones in their households.

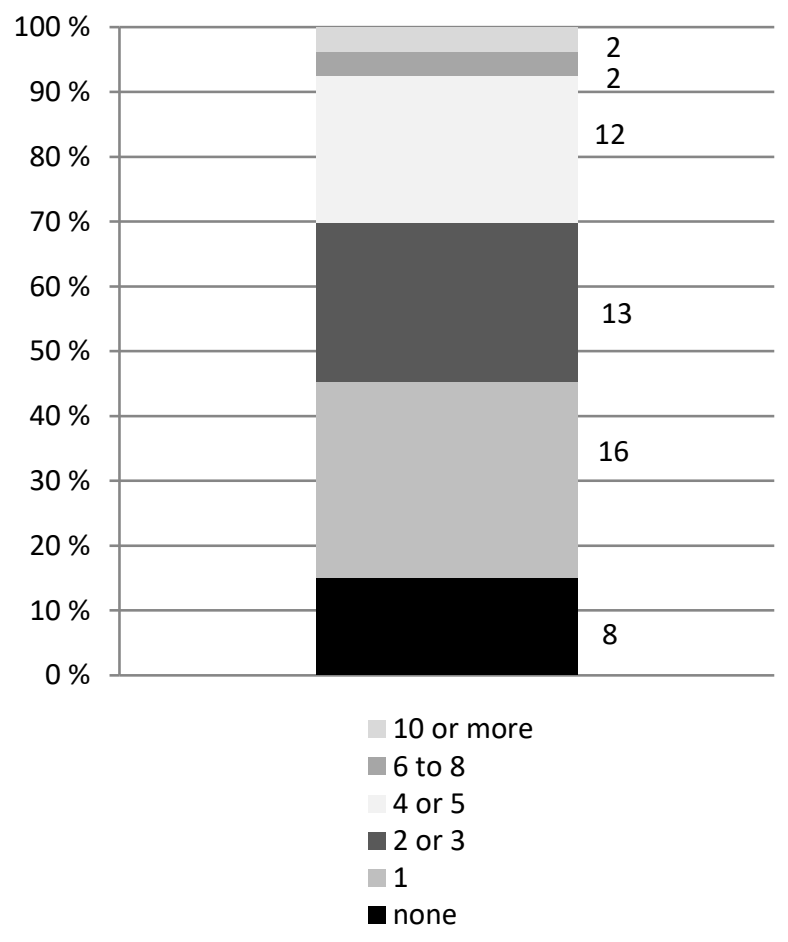

Fig. 2. Number of end-of-use phones stored at homes (respondents $R=53$ ). 
In total, 37 respondents ( $70 \%$ of all or $82 \%$ of those who had mobile phones at homes) told that they just stored the phones at home (see the reasons in Fig. 4), while 25\% have also given at least one unused phone to children, relatives or friends. Only $4 \%$ have sold an unused mobile phone onward and $13 \%$ of respondents have left it at the store when buying a new one. Further, $28 \%$ of respondents have taken old mobile phones to the recycling centre but none of them stated to have disposed them with mixed waste. The fate of the old mobile phones is illustrated in Fig. 3.

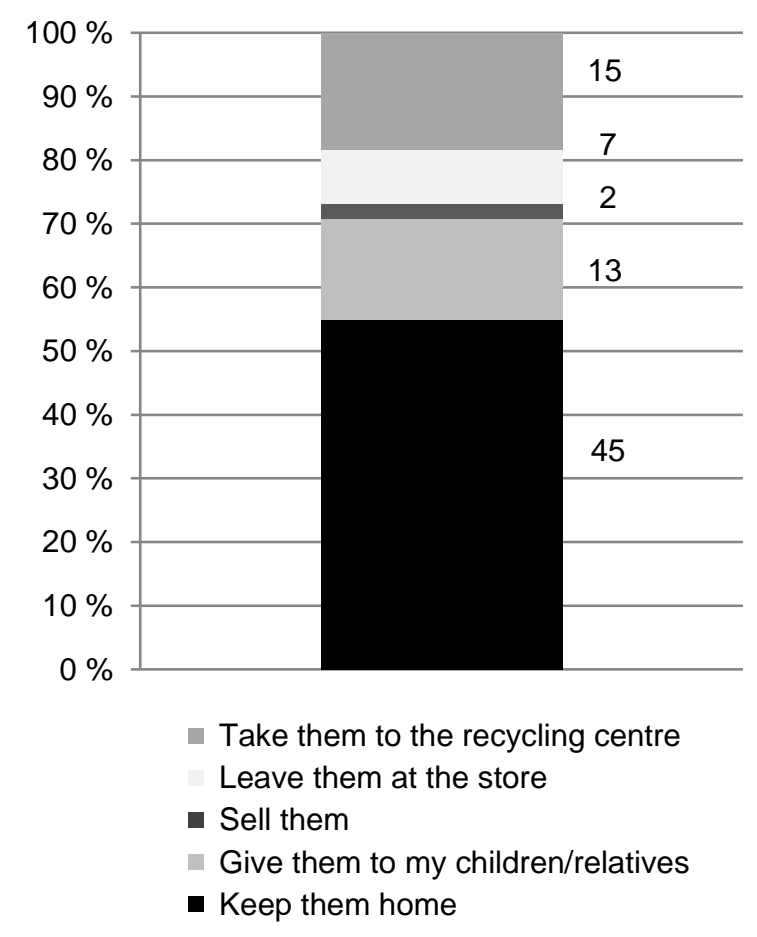

Fig. 3. The fate of old mobile phones (respondents $R=53$, responses $n=82$ ).

Respondents had various reasons for not returning old mobile phones. The most common reason was to keep them as spare phones; $55 \%$ of respondents agreed on this. Further, $38 \%$ notified that end-of-use phones lay at homes because they have not gotten around to returning it yet. Less than $4 \%$ of respondents felt that recycling was troublesome; however, $17 \%$ did not know where to take old phones. Reasons for not returning the mobile phones are summarized in Fig. 4. The relation between the number of stored phones and the reasons for not returning them can be examined more in detail. Thirteen ( $25 \%$ of all) respondents stated to have 2-3 unused phones at homes. Up to $69 \%$ of them argued to keep the phones in reserve; however, $44 \%$ of them mentioned that there was also some other reason for storing. When considering households having 4 or more phones at home (30\% of all respondents), the reason of keeping them as a spare phone decreased slightly to $63 \%$, whereas the share of other reasons rose to $70 \%$. Five (31\%) respondents claim that they don't know where to return them, while $9(56 \%)$ of them admitted not gotten around to do it yet. Further, two (13\%) respondents reported both reasons. On the other hand, there were also $8 \%$ of respondents, who argued to have only spare phones although the number of unused phones was higher than the number of persons living in their households. All in all, respondents who stated to keep phones only in reserve, have fewer phones at homes (2.7 phones) on average than the respondents keeping phones for some other reasons. Respondents, 
who claimed not knowing where to take them, had an average of 3.8 unused phones at home, and those, who have not gotten around to returning them yet, had 4.3 phones on average.

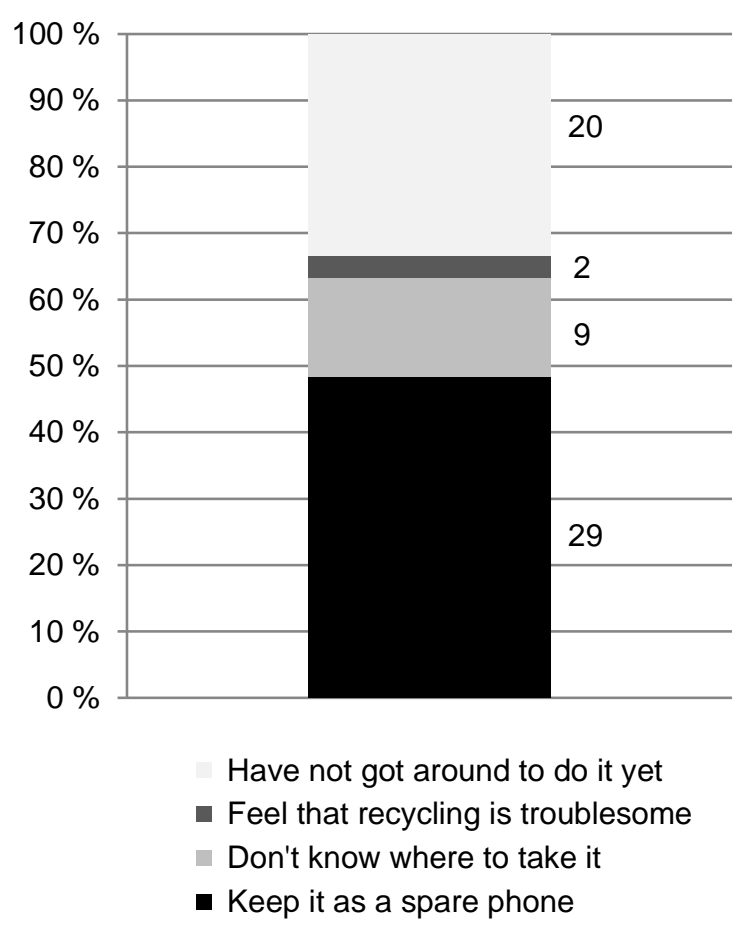

Fig.4. Reasons for not returning old mobile phones (respondents $R=53$, responses $n=60$ ).

Old mobile phones were returned to the recovery system through several routes. Most commonly, respondents returned old phones to the main collection point of Oulu Waste Management Company's Rusko Waste Centre (23\%) but also collection points in certain working places (6\%) and in-store reception (6\%) were occasionally used. Further, some respondents (4\%) had participated in special collection campaigns through public postal services. When the convenience of current recovery system was enquired, $30 \%$ of respondents regarded that it was simple to take old mobile phones to the recycling centre while only $4 \%$ viewed it as troublesome. However, most of the respondents $(66 \%)$ did not take a stand on the question.

When asking for a frequency of changing mobile phones, none of the respondents admitted to changing a mobile phone more often than once a year. $9 \%$ of respondents had replaced their mobile phones in the course of the first two years, while most commonly (57\%) mobile phones were changed in 2 to 3 years. Moreover, $34 \%$ of respondents had used their mobile phones longer, up to 10 years. Majority of the respondents $(72 \%)$ notified that they would not change a mobile phone unless the old one stopped working properly. However, respondents agreed to change mobile phones also if the latest models had novel features (32\%) or if mobile phones were company-owned (17\%).

\subsection{Consumer awareness}

Respondents were unanimous when asking the importance of recycling old mobile phones; all but three persons agreed with the statement. Totally, $74 \%$ of respondents argued more specifically for the reasons of importance. Half of them considered recycling to be important due to material recovery, especially in the form of metal recycling, but also due to re-use potential of functional components or even whole devices. In addition 
to the resource efficiency point of view, environmental protection was mentioned often (38\%) in the responses. Further, materials used in mobile phones were also in the focus of reasoning for recycling; hazardous materials were the main concern of $28 \%$ of respondents while, on the other hand, precious metals and other valuable materials contained in EEE were also highlighted several times. Totally $28 \%$ of respondents regarded recycling as important due to the high economic value of WEEE or other economic issues. Reasons for the importance of mobile phone recycling are summarized in Fig. 5.

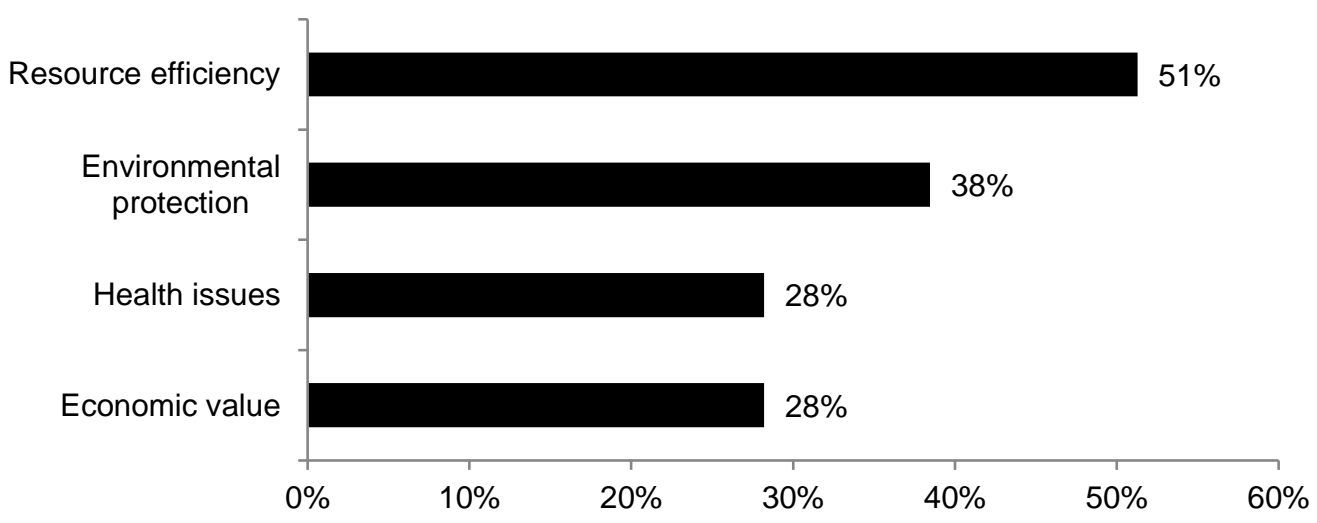

Fig. 5. Motives for recycling old mobile phones (respondents $R=39$ ).

When asking about Finnish WEEE legislation, more than half of the respondents (57\%) were aware of the Government Degree concerning WEEE recovery in Finland. However, the practical realisation of the WEEE legislation was more familiar; over $95 \%$ of respondents were aware that households do not have to pay a recycling fee when returning end-of-use devices to the official collection system. Only one person did not know about that possibility yet. Further, $43 \%$ of respondents had seen the symbol used for marking EEE in their mobile phones or its supplementaries, typically in batteries or manuals. On the other hand, as much as $36 \%$ responded negatively to the question. The rest $(21 \%)$ did not take a stand on the issue. Moreover, $36 \%$ did not define the meaning of the symbol but, alternatively, everyone who responded the question (64\%) was able to identify the main thoughts of the symbol correctly.

\subsection{Consumers' perceptions towards monetary incentives of recycling and mobile phone re-use}

Respondents were asked to define the sum of money that would motivate them to return old mobile phones through a deposit system similar to returnable bottles. Thirteen per cent $(13 \%)$ of the respondents would be content with one euro, while a one third of respondents would be satisfied with 5 euros maximum. Altogether, $57 \%$ of respondents claimed that a 10 euro deposit would motivate them to return old mobile phones through a deposit system. A 20 euros deposit would please $70 \%$ of respondents.

When asking respondents' willingness to buy a used mobile phone, $51 \%$ of them answered positively with certain reserves, as illustrated in Fig. 6. According to the respondents, a cheaper price is the most important prerequisite $(41 \%)$ for buying a used phone. It is also the most commonly cited reason with the frequency of $38 \%$. The novel features (23\%) and knowing the last owner (19\%) of a used mobile phone are also relatively common factors when making a decision. Additionally, the age is a prerequisite to $15 \%$ of respondents; however, no more than $4 \%$ of respondents consider it as the most relevant factor. Five respondents did not define the most important prerequisite at all. 


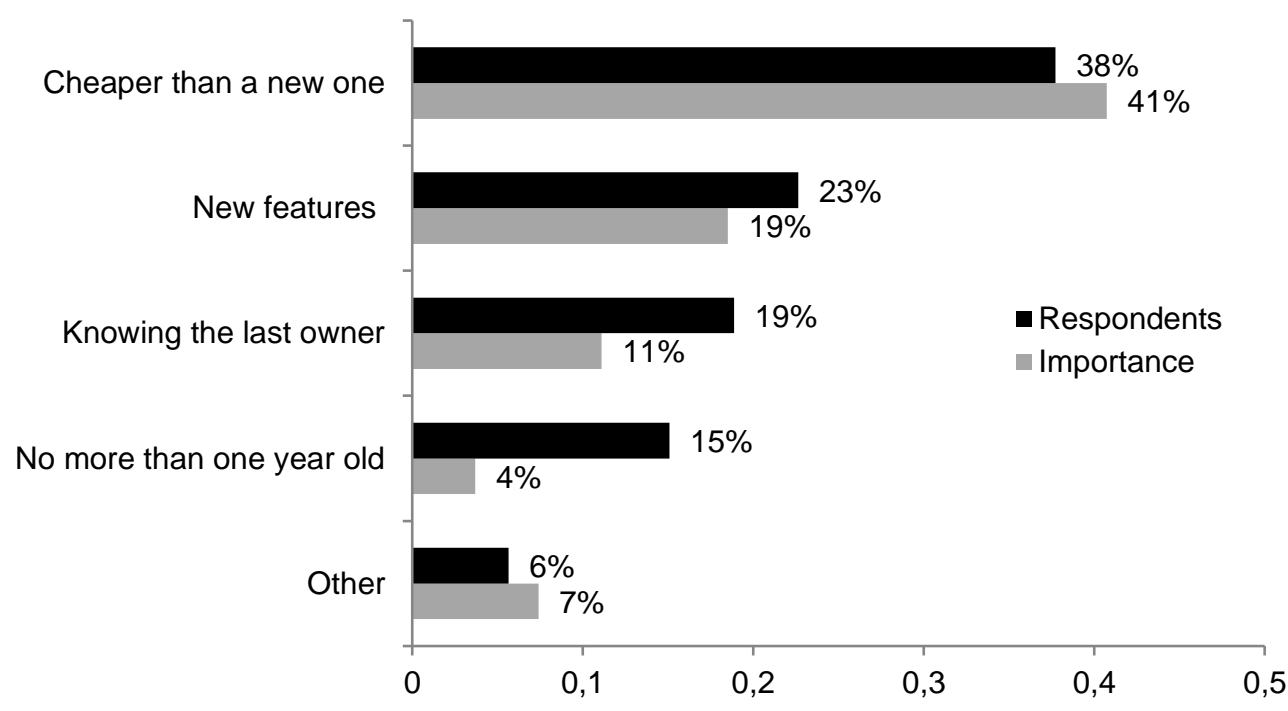

Fig. 6. Importance of prerequisites for buying a used mobile phone (respondents $R=27$, prerequisites $n=53$ ).

Respectively, $49 \%$ of respondents stated that they are not willing to buy a used mobile phone of which $73 \%$ argued more specifically for the reasons, as illustrated in Fig. 7. According to the respondents, the suspicion toward reliability was the most common reason (32\%); $47 \%$ of respondents agreed on this. Also a short span of mobile phones due to fast technical progress $(21 \%)$ and the existence of new budget models (21\%) were the prevalent reasons for not buying a used mobile phone. Further, some of respondents thought highly of valid warranty $(16 \%)$ or certain specific features $(7 \%)$; however, only one respondent mentioned information security issues being an inhibitory reason.

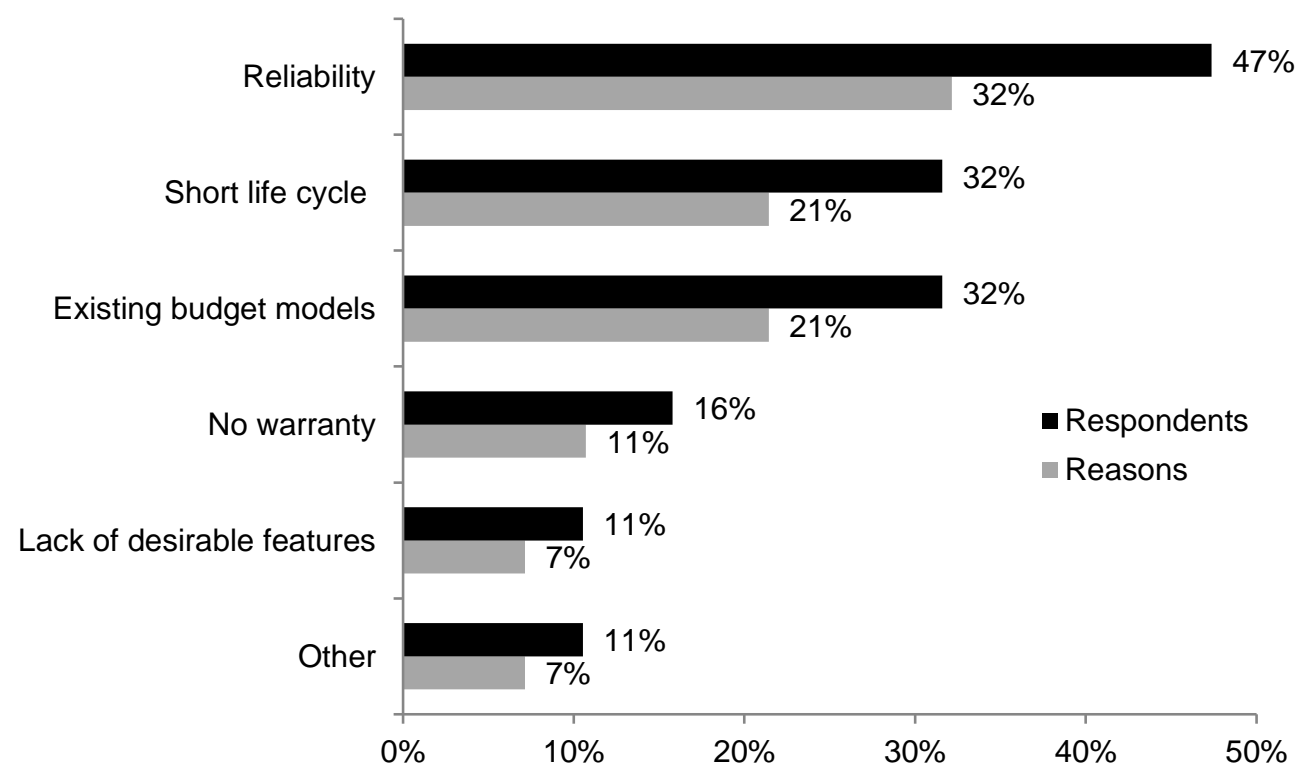

Fig. 7. Reasons for not buying a used mobile phone (respondents $R=19$, reasons $n=28$ ).

Also opinions concerning reasonable prices for used mobile phones (max. $€$ or $\%$ from original price) were enquired from those who were compliant to mobile phone re-use. Totally, $78 \%$ of them were willing to pay a maximum of $50 \%$ from the original price, while $15 \%$ were ready to pay up to $80 \%$ or 300 euros. 


\section{Discussion}

\subsection{Research Question 1: What are the reasons of failing to return mobile phones for recycling?}

Mobile phones are a typical 'up-to-date' product defined by Cox et al. (2013); they have ordinarily a short lifetime and are often discarded before the end of their functional life. This is true also in case of Oulu. According to the survey, consumers typically buy a new mobile phone every 2-3 years. The respondents claimed it is because the old phones have stopped working properly. However, they further claim to keep them at homes as spare phones rather than returning them immediately when purchasing a new one. This would indicate that the phones are still functional after all. The other commonly mentioned reason is that consumers have not gotten around to returning them yet. Both reasons indicate the reluctance to cede ownership. As this phenomenon seems to be especially true for every-day use of personal electronics such as mobile phones, we could argue that the reason to this is the personal attachment to the device. We speculate that many tend to personalize their mobile phones and, therefore, they become a representation of personality and style (Cui et al., 2007; Vanden Abeele et al., 2014), and it takes time for this attachment to subside and the owner willing to part with the device. During this time, the owner might simply forget about the old device. Because of the fast technological progress, it is highly unlikely that those "spare" phones will ever be used again considering that mobile phones are a typical "up-to-date" product category. Currently, there seems to be an immense resource potential stored at homes, waiting for the storage phase to end (Bouvier and Wagner, 2011; Polák and Drápalová, 2012; Saphores et al., 2009; Toppila, 2011). Beyond the need to correct this behaviour, it is also necessary to devise ways to motivate citizens to collect their unused extra phones from storage and return them for recycling. We argue, firstly, that consumers have to be made aware that there is still a value in the product that could be recovered through re-use, refurbishment, or material recovery and, secondly, that they need to be offered a compensation to provide sufficient motivation for action. Especially in case of owners who fall in the "have not got around to do it yet" category, providing a reimbursement might be a sufficient reminder and incentive to return old phones for recycling. However, further empirical studies will be needed to verify this assumption.

5.2 Research Question 2: Are consumers aware of possibilities to return WEEE and what are consumers' perceptions related to feasibility of the current WEEE collection network in the Oulu Region?

Several studies have shown that the convenience of a WEEE recycling system has an influence on public participation and also recovery rates (Saphores et al., 2012; Yin et al., 2013). In Finland, a convenient nationwide collection network is required by law. In the survey, people were asked about their actual recycling actions and thoughts related to the feasibility of the current system. Based on the results, we can conclude that the current regional WEEE collection network is relatively well-known among local residents. Permanent collection points are the most commonly used for returning old mobile phones even though several other returning options are also available. The current permanent collection points are regarded simple to use; however, the high home-storage rates indicate that proximity and convenience are inadequate for motivating the return of small WEEE. We expect a change to this, as the retailer take-back option for small WEEE was made mandatory in May 2013 by the Finnish Waste Act (Ministry of the Environment in Finland, 2011). As a consequence, numerous in-store collection points have been established across the country within the last year. Wagner et al. (2013) found that the practical implementation of retailers' take-back (e.g. placement of containers) has a significant influence on the convenience and, hence, also on collection rates. However, there 
is no accurately dictated implementation for in-store reception in Finland. Shops are only required to finance and provide a space for the WEEE receptacles, the requisites and work contributions needed are their prerogative. Distributors may e.g. forward the received WEEE to the official collection network by themselves or, alternatively, they may enrol in a distributors register in order to obtain free unloading services financed by Finnish EEE producers associations.

According to the Association of Electric and Electronics Manufacturers and Importers (SERTY), amounts of received small-WEEE from in-store reception points are still low but volumes are expected to rise rapidly as soon as consumers will become more aware of this return option. Therefore, it would be highly recommended that Finnish authorities, producer associations and retailers will provide increased publicity and up-to-date information on prevailing practises through nationwide campaigns over the implementation period of in-store reception points.

\subsection{Research Question 3: Are consumers aware of the importance of mobile phone recycling?}

Increased information and environmental awareness has been proven to enhance public participation of recycling (Ramayah et al., 2012; Saphores et al., 2012; Thomas and Sharp, 2013; do Valle et al., 2004). However, knowledge of importance and existence of recovery systems in itself does not bring about proenvironmental behaviour. On the grounds of the survey, it seems that the awareness of the importance of mobile phone recycling is relatively high also in Oulu. Most are aware of the existence of a WEEE recovery system; however, only a part of them have chosen to take use of it yet. In other words, the case is that awareness has not translated to behaviour. Respondents were unanimous when asking the importance of recycling old mobile phones; however, even though as much as $35 \%$ of motives were linked to resource efficiency, up to $85 \%$ of the respondents store their non-used mobile phones at home until a possible future use. To change this attitude of consumers is a fundamental requirement for sustainable waste management. Here we argue that awareness and incentive are the decisive factors; the key is that there is still a value in the product. Incentives could be a good option to change this behaviour; up to half of respondents would be motivated to return old mobile phones through a deposit system for fairly reasonable (max. 5 euros) monetary incentives. Therefore, consideration of implementing economic incentives to foster mobile phone recycling is advisable also in Finland.

\subsection{Research Question 4: What are the consumers' perceptions toward the re-use of mobile phones?}

The WEEE Directive places great stress on building recovery infrastructures that facilitate re-use. The short life-cycle of EEE has a significant impact on re-use potential of functional WEEE and it can be easily lost in the course of purposeless storing (Babbitt et al., 2011; Kissling et al., 2013). Therefore, to facilitate re-use of electronics, consumers will need to be committed to return these end-of-use electronics to WEEE recovery centres without delay. Based on the results of the survey, there is a lot of room for improvements in this behaviour; especially since novel features and age of mobile phones are typical factors considered when making a decision to buy a used mobile phone. Based on the survey, an establishment of a testing and refurbishing system is needed, to provide verification on the quality of the device and thus enhance re-use. In previous years, certain efforts existed but the national markets of refurbished EEE in Finland were rather restricted and, unfortunately, activities have gradually waned over the time. All in all, only half of people have an open mind about the re-use of mobile phones; however, it seems that the supply and demand of refurbished 
mobile phones do not meet at this moment in Finland due to consumer's unrealistic expectations of new features, valid guarantee time and low prizes. Therefore, consumer awareness raising measures and attitudinal changes of consumers are presumed before Finnish re-use markets of mobile phones will turn economically viable.

\subsection{Evaluation of the survey}

Even though conducting a survey via mail offers advantages, such as possibility to detailed questions and eliminating the interviewer's bias (Saphores et al., 2006), the execution of the survey included also some weaknesses. Firstly, mail surveys tend to have a relatively low response rate (Saphores et al., 2006); in this case, the response rate was $35 \%$. Another issue is voluntariness to participate in mail surveys. In the survey in question, an exceptional large proportion of respondents was highly educated; almost $80 \%$ of the respondents notified to hold a polytechnic or university degree, whereas only $39 \%$ of the whole Finnish population of aged 25-64 years have that kind of tertiary education (OECD, 2014). It indicates that welleducated people have high general awareness of environmental issues and, therefore, they also considered answering the survey to be important. The phenomenon may have an influence on the results in general and, therefore, the results of this survey are only suggestive for further research.

\section{Conclusions}

The purpose of this paper was to gather valuable information about consumers' recycling behaviour and perceptions of the current WEEE recovery system in Finland. The study was conducted as a survey in the city of Oulu in 2013 to find out if consumers are aware of possibilities and the importance of returning WEEE for recycling and, further what are the current reasons of not returning their old mobile phones for recycling. Moreover, consumers' perceptions toward the re-use of mobile phones and possible prerequisites were enquired.

On the grounds of the survey, we can conclude that the current regional WEEE collection network seems to be relatively well-known among local residents. Respondents of the survey stated to be aware of the existence of a WEEE recovery system but, for one reason or another, only half of them chose to take use of it. When mobile phones are returned, permanent collection points are most commonly used. Permanent collection points are regarded simple to use; however, the high storing rate at homes indicates that proximity and convenience of the current system is inadequate to motivate the return of small WEEE. Therefore, the reuse potential of end-of-life mobile phones is significantly underused at present.

It seems that the awareness of the importance of mobile phone recycling is considerable high; notwithstanding, awareness has not translated to behaviour. The survey revealed that up to $85 \%$ of the users store their non-used mobile phones at home until a possible future use, which may never come. To change this attitude of consumers is a fundamental requirement for sustainable waste management. There is a huge potential in the resources currently stored at homes, waiting for the recycling culture to evolve so that WEEE recovery will be a mainstream activity. Considering the behaviours that need to change if we wish to achieve a more sustainable society, the behavioural scope of interventions is of the utmost importance.

The short social life-cycle of EEE has a significant impact on the re-use potential of functional WEEE and it can be easily lost in the course of purposeless storing. Therefore, to facilitate re-use, and the highest level of recovery, consumers will need to be committed to return these end-of-use electronics to WEEE recovery 
centres without delays. The survey points out, that there is an explicit need for more information and publicity on the mobile phone recovery in Finland, especially up-to-date information on retailers' take-back, to change current storing habits of consumers. Further, consumers need to be aware that the recovery costs are embedded in the price of mobile phone and, therefore, the more active use of the WEEE recovery system should be a public spirit. However, we argue that a monetary deposit system should be considered in the case of valuable electronics such as mobile phones, in order to motivate the return for recovery. It is also expected that raising consumer awareness will lead to more environmentally sound behaviour and, ultimately, improved WEEE recovery efficiency.

\section{Acknowledgements}

Financial support of the Thule Institute's Research Programme at the University of Oulu is gratefully acknowledged.

\section{References}

Ajzen, I.,1991. The theory of planned behavior. Organizational Behaviour and Human Decision Processes 50, $179-211$.

Arditi, S., 2014. CSO input on consumer awareness and behavior with regards WEEE. In: 2nd EU Civil SocietyIndustry Dialogue on "Urban Mines, Consumer Behaviour and Producer Responsibility in a Circular Economy". Brussels, June 6, 2014. Retrieved September 22, 2014, from http://www.cobaltfp7.eu/events/EU_dialogue_2

Babbitt, C.W., Williams, E., Kahhat, R., 2011. Institutional disposition and management of end-of-life electronics. Environmental Science and Technology 45, 5366-5372.

Barr, S., Gilg, A.W., Ford, N.J., 2001. A conceptual framework for understanding and analysing attitudes towards household-waste management. Environment and Planning A 33, 2025-2048.

Bernstad, A., la Cour Jansen, J., Aspegren, H., 2011. Property-close source separation of hazardous waste and waste electrical and electronic equipment - a Swedish case study. Waste Management 31, 536-543.

Bernstad, A., la Cour Jansen, J., Aspegren, H., 2012. Local strategies for efficient management of solid household waste - a full-scale Augustenborg experiment. Waste Management and Research 30, 200212.

Bigum, M., Petersen, C., Christensen, T.H., Scheutz, C., 2013. WEEE and portable batteries in residual household waste: quantification and characterisation of misplaced waste. Waste Management 33, 23722380 .

Bouvier, R, Wagner, T., 2011. The influence of collection facility attributes on household collection rates of electronic waste: The case of televisions and computer monitors. Resources, Conservation and Recycling, 55, 1051-1059.

Chancerel, P., 2010. Substance flow analysis of the recycling of small waste electrical and electronic equipment - an assessment of the recovery of gold and palladium (Doctoral Dissertation). Technical University of Berlin, Germany.

Cox, J., Griffith, S., Giorgi, S., King, G., 2013. Consumer understanding of product lifetimes. Resources, Conservation and Recycling 79, 21-29. 
Cui, T., Chipchase, J., Ichikawa, F., 2007. A cross culture study on phone carrying and physical personalization. Aykin, N. (ed.) Usability and Internationalization, Part I, HCII 2007, LNCS 4559, pp.483492.

Darby, L., Obara, L., 2005. Household recycling behaviour and attitudes towards the disposal of small electrical and electronic equipment. Resources, Conservation and Recycling 44, 17-35.

Directive 2012/19/EU of the European Parliamant and of the Council of 4 July 2012 on waste electrical and electronic equipment (WEEE). Text with EEA relevance. (2012). Official Journal 24.7.2012;L197.

Environmental Data Centre on Waste, 2014. Waste Electrical and Electronic Equipment (WEEE). Retrieved August 6, 2014, from Eurostat database. http://epp.eurostat.ec.europa.eu/portal/page/portal/waste/key_waste_streams/waste_electrical_electroni c_equipment_weee

Eurostat, 2014. Waste statistics - electrical and electronic equipment. Retrieved September 5, 2014, from http://epp.eurostat.ec.europa.eu/statistics_explained/index.php/Waste_statistics__electrical_and_electronic_equipment

Fullerton, D., Kinnaman, T., 1995. Garbage, recycling and illegal burning or dumping. Journal of Environmental Economics and Management 29, 78-91.

Gutiérrez, E., Adenso-Días, B., Lozano, S., González-Torre, P., 2010. A competing risks approach for time estimation of household WEEE disposal. Waste Management 30, 1643-1652.

Herold, M., 2007. A Multinational Perspective to Managing End-of-Life Electronics. Doctoral Dissertation, Helsinki University of Technology, Espoo, Finland, 2007.

Huisman, J., Magalini, F., Kuehr, R., Maurer, C., Delgado, C., Artim, E., Stevels, A.B.L., 2007. 2008 Review of Directive 2002/96 on Waste Electrical and Electronic Equipment (WEEE) (No. 07010401/2006/442493/ETU/G4). Bonn, Germany: United Nations University. Retrieved August 25, 2014, from http://ec.europa.eu/environment/waste/weee/pdf/final_rep_unu.pdf

Kissling, R., Coughlan, D., Fitzpatrick, C., Boeni, H., Luepschen, C., Andrew, S., Dickenson, J., 2013. Success factors and barriers in re-use of electrical and electronic equipment. Resources, Conservation and Recycling 80, 21-31.

Kissling, R., Fitzpatrick, C., Boeni, H., Luepschen, C., Andrew, S., Dickenson, J., 2012. Definition of generic re-use operating models for electrical and electronic equipment. Resources, Conservation and Recycling 65, 85-99.

Kollmuss, A., Agyemann, J., 2002. Mind the Gap: Why do people act environmentally and what are the barriers to pro-environmental behavior? Environmental Education Research 8, 239-260.

Krook, J., Eklund, M., 2010. The strategic role of recycling centres for environmental performance of waste management systems. Applied Ergonomics 41, 362-367.

Melissen, F.W., 2006. Redesigning a collection system for "small" consumer electronics. Waste Management 26, $1212-1221$.

Miafodzyeva, S., Brandt, N., Andersson, M., 2013. Recycling behaviour of households living in multicultural urban area: a case study of Järva, Stockholm, Sweden. Waste Management \& Research 31, 447-457.

Milovantseva, N., Saphores, J.-D., 2013. E-waste bans and U.S. households' preferences for disposing of their e-waste. Journal of Environmental Management 124, 8-16. 
Ministry of the Environment in Finland, 2011. Waste Act 646/2011, amendments up to 410/2014 included. Retrieved August 25, 2014, from http://www.finlex.fi/fi/laki/alkup/2014/20140410

Ministry of the Environment in Finland, 2014. Government Degree 519/2014 on WEEE. Retrieved September 5, 2014, from http://www.finlex.fi

OECD, 2014. Education at a Glance 2014: OECD Indicators. OECD Publishing. Retrieved September 5, 2014, from http://dx.doi.org/10.1787/eag-2014-en

Ongondo, F.O., Williams, I.D., 2011. Mobile phone collection, reuse and recycling in the UK. Waste Management 31, 1307-1315.

Ongondo, F.O., Williams, I.D., Cherrett, T.J., 2011. How are WEEE doing? A global review of the management of electrical and electronic wastes. Waste Management 31, 714-730.

Palmer, K., Sigman, H., Walls, M., 1997. The cost of reducing solid waste. Journal of Environmental Economics and Management 33, 128-150.

Pérez-Belis, V., Bovea, M.D., Gómez, A, 2013. Waste electric and electronic toys: management practices and characterisation. Resources, Conservation and Recycling 77, 1-12.

Peagam, R., McIntyre, K., Basson, L., France, C., 2013. Business-to-business information technology user practices at end of life in the United Kingdom, Germany, and France. Journal of Industrial Ecology 17, 224-237.

Polák, M., Drápalová, L., 2012. Estimation of end of life mobile phones generation: the case study of the Czech Republic. Waste Management 32, 1583-1591.

Pongrácz, E., Ylä-Mella, J., Tanskanen, P., Keiski, R., 2008. Conceptual analysis of electronic waste: revisiting the definition of waste and the classes of waste. In: I. Zandi, R.L. Mersky \& W.K. Shieh (eds.), Proceedings of 23rd International Conference on Solid Waste Technology and Management Chester, PA: Widener University. pp. 359-365.

Ramayah, T., Lee, J.W.C., Lim, S., 2012. Sustaining the environment through recycling: an empirical study. Journal of Environmental Management 102, 141-147.

Saphores, J.-D.M., Nixon, H., 2014. How effective are current household recycling policies? Results from a national survey of U.S. households. Resources, Conservation and Recycling 92, 1-10.

Saphores, J.-D.M., Nixon, H., Ogunseitan, O.A., Shapiro, A. A., 2006. Household willingness to recycle electronic waste: an application to California. Environment and Behavior 38, 183-208.

Saphores, J.-D.M., Nixon, H., Ogunseitan, O.A., Shapiro, A. A., 2009. How much e-waste is there in the US basements and attics? Results from a national survey. Journal of Environmental Management 90, 33223331.

Saphores, J.-D.M., Ogunseitan, O.A., Shapiro, A. A., 2012. Willingness to engage in a pro-environmental behaviour: an analysis of e-waste recycling based on a national survey of U.S. households. Resources, Conservation and Recycling 60, 49-63.

Sigman, H., 1995. A comparison of public policies for lead recycling. Rand Journal of Economics 26, 452-478.

Staats, H., Harland, P., Wilke, H.A.M., 2004. Effecting durable change: a team approach to improve environmental behaviour in the household. Environment and Behavior 36, 341-367.

Stern, P.C., 2000. Toward a coherent theory of environmentally significant behavior. Journal of Social Issues $53,407-424$

Tanskanen, P., 2013. Management and recycling of electronic waste, Acta Materialia 61, 1001-1011. 
Tanskanen, P., Butler, E., 2007. Mobile phone take back - learning's from various initiatives. In: Proceedings of IEEE International Symposium on Electronics and the Environment. Piscataway, NJ: IEEE Conference and Custom Publishing Department. pp. 206-209.

Thomas, C., Sharp, V., 2013. Understanding the normalization of recycling behaviour and its implication for other pro-environmental behaviours: a review of social norms and recycling. Resources, Conservation and Recycling 79, 11-20.

Toppila, A., 2011. Waste flows in Finnish Producer Responsibility System - case WEEE and portable batteries and accumulators [Master's Thesis] (in Finnish). University of Jyväskylä, Finland.

do Valle, P., Reis, E., Menezes, J., Rebelo, E., 2004. Behavioral determinants of household recycling participation: the Portuguese case. Environment and Behavior 36, 505-540.

Wagner, T.P., 2013. Examining the concept of convenient collection: an application to extended producer responsibility and product stewardship frameworks. Waste Management 33, 499-507.

Wagner, T.P., Toews, P. Bouvier, R., 2013. Increasing the diversion of household hazardous wastes and materials through mandatory retail take-back. Journal of Environmental Management 123, 88-97.

Wang, Z., Zhang, B., Yin, J., Zhang, X., 2011. Willingness and behaviour towards e-waste recycling for residents in Beijing city. Journal of Cleaner Production 19, 977-984.

Vanden Abeele, M., Antheunis, M.L., Schouten, A.P., 2014. Me, myself and my mobile: A segmentation of youths based on their attitudes towards the mobile phone as a status instrument. Telematics and Informatics, 31, 194-208.

Yin, J., Gao, Y., Xu, H., 2014. Survey and analysis of consumers' behaviour of waste mobile phone recycling in China. Journal of Cleaner Production 65, 517-525.

Ylä-Mella, J., Poikela, K., Lehtinen, U., Keiski, R.L., Pongrácz, P., 2014. Implementation of Waste Electrical and Electronic Equipment Directive in Finland: evaluation of the collection network and challenges of the effective management. Resources, Conservation and Recycling 86, 38-46.

Ölander, F., Thøgersen, J., 1995. Understanding of consumer behaviour as a prerequisite for environmental protection. Journal of Consumer Policy 18, 345-385. 